\title{
Current Exercise Behaviors of Breast Cancer Patients Diagnosed with Che- motherapy-induced Peripheral Neuropathy
}

Karen Y. Wonders ${ }^{1,2 *}$ and Daniel G. Drury ${ }^{3}$

${ }^{1}$ Department of Health, Physical Education and Recreation, Wright State University, 316 Nutter Center, 3640 Colonel, Glenn Hwy, Dayton, OH 45435, USA ${ }_{2}^{2}$ Maple Tree Cancer Alliance, 106 Peach Orchard Ave, Dayton, OH, 45419, USA

${ }^{3}$ Gettysburg College, Department of Health Sciences, 300 N. Washington Street, Gettysburg, PA 17325, USA

\begin{abstract}
Introduction: Chemotherapy-induced peripheral neuropathy (CIPN) is a common, dose-limiting effect of cancer therapy. The neuropathic pain associated with CIPN often has negative implications on an individual's quality of life (QOL) and has long been recognized as one of the more difficult types of pain to treat. Treatment of neuropathic pain due to CIPN often requires a multidisciplinary approach, with much attention focused on the use of pharmacological therapies. However, in most instances, these agents have been shown to have additional negative side effects for cancer patients. Thus, other interventions that address the symptoms of CIPN should be considered. One such possible intervention is exercise rehabilitation, which has previously been reported effective in attenuating numerous cancer treatment-related toxicities and enhancing the QOL of patients. However, to our knowledge, there have been no published clinical trials examining the role of exercise in preserving neurological function following chemotherapy. As such, the purpose of this investigation was to examine the current exercise habits of breast cancer patients who are diagnosed with CIPN and the impact on pain and QOL.
\end{abstract}

Methods: 300 women listed in the Breast Cancer Registry of Greater Cincinnati database were recruited by mail and asked to complete three questionnaires (McGill QOL, Leeds Assessment of Neuropathic Symptoms and Signs, and Current Exercise Behaviors). Data was analyzed at the 0.05 level of significance using a student's t-test and a Pearson's product moment correlation.

Results: 134 completed surveys were returned and analyzed (44.6\% response rate). Overall, QOL and exercise behaviors were moderately correlated $(r=0.56)$. Patients reported exercising an average of $2.3 \mathrm{~d} / \mathrm{wk}$ and an overall $\mathrm{QOL}$ of 4.7. Of the patients completing the recommended amount of physical activity $(E X, n=21), Q O L$ was 6.3 , which was significantly higher than patients who did not meet these recommendations (SED, $n=113, p<0.001)$. Likewise, only $15 \%$ of EX patients reported experiencing pain compared to $72 \%$ of SED patients $(p<0.001)$. Conclusions: Based on these data, it seems likely that an exercise intervention would be successful in attenuating symptoms of CIPN and improving the overall QOL of breast cancer patients.

Keywords: Chemotherapy-induced peripheral neuropathy; Exercise behaviors; Quality of life; Pain

\section{Introduction}

Chemotherapy- induced peripheral neuropathy (CIPN) is a common ailment among those taking chemotherapeutic drugs. This condition is characterized by damage to the nervous system that is a direct result of the medications associated with chemotherapy. Little is known about the mechanisms responsible for the development of CIPN [1]. The peripheral toxicity involved with CIPN is specific to each chemotherapy drug class, and in most cases, appears to be dose and duration dependent, however it can evolve even after a single drug application [2]. The chemotherapy agents Docetaxel, Paclitaxel, or Vinorelbine are used to treat breast cancer, and often result in damage to central nervous system pain pathways, resulting in neuropathic pain [3-6]. The presence and severity of neuropathic pain is often shown to be associated with impairments in walking, general activities, sleep, work, mood, enjoyment of life, and relationships with others $[7,8]$.

Much effort has been made to explore pharmacological therapies to reduce CIPN. Some of these therapies provide modest improvements in neurological function. However, in most instances, these agents have been shown to have additional negative side effects for cancer patients, such as cardiac conduction defects, abnormalities in antidiuretic hormone secretion, loss of balance, swelling in extremities, tremor, and increased chemotherapy resistance [9-11]. Thus, other interventions that address the symptoms of CIPN should be considered. One intervention that has the potential of preventing or alleviating CIPN is exercise reha- bilitation. Exercise has been shown to have a local effect on peripheral nerves, inducing changes in both the vasculature and metabolic systems [12]. Short-term exercise stimulates endothelium-dependent vasodilatation and endoneurial blood flow [13]. Long-term exercise has a positive effect on oxygen delivery, as increased blood flow exposes blood vessels to shear stress, which augments vasodilation [13]. Several studies have illustrated the beneficial effects of exercise in attenuating numerous cancer treatment-related toxicities and enhancing the quality of the lives of patients [14-21]. In addition, numerous studies on the effect of exercise in populations with diabetic peripheral neuropathy have produced promising results [22-24]. However, published clinical trials examining the role of exercise in preserving neurological function following chemotherapy are limited. Since breast cancer survivors represent the largest population of cancer survivors in the United States,

${ }^{*}$ Corresponding author: Karen Y. Wonders, Wright State University, Department of Health, Physical Education and Recreation, Wright State University, 316 Nutter Center, 3640 Colonel Glenn Hwy, Dayton, OH 45435, USA, Tel: 937-775-2637; Fax: 937-775-4252; E-mail: karen.wonders@wright.edu

Received March 08, 2012; Accepted April 25, 2012; Published April 27, 2012

Citation: Wonders KY, Drury DG (2012) Current Exercise Behaviors of Breast Cancer Patients Diagnosed with Chemotherapy-induced Peripheral Neuropathy. J Integr Oncol 1:103. doi:10.4172/2329-6771.1000103

Copyright: (c) 2012 Wonders KY, et al. This is an open-access article distributed under the terms of the Creative Commons Attribution License, which permits unrestricted use, distribution, and reproduction in any medium, provided the original author and source are credited. 
Citation: Wonders KY, Drury DG (2012) Current Exercise Behaviors of Breast Cancer Patients Diagnosed with Chemotherapy-induced Peripheral Neuropathy. J Integr Oncol 1:103. doi:10.4172/2329-6771.1000103

Page 2 of 4

the purpose of this investigation was to examine the current exercise behaviors of breast cancer patients who were diagnosed with CIPN and to determine the resulting impact on their pain and quality of life.

\section{Methods}

\section{Subjects}

This investigation used a non-probability sample of convenience. Women who met the eligibility criteria and were listed in the Breast Cancer Registry of Greater Cincinnati (BCRGC) database were recruited by mail in the fall of 2010. The eligibility criteria included women who (a) have recently received a clinical diagnosis of CIPN, and (b) were currently taking the chemotherapy agents Docetaxel, Paclitaxel, or Vinorelbine, and (c) were able to read and write English. The BCRGC is a database established by the University of Cincinnati, Department of Environmental Health for the purpose of supporting studies that focus on breast cancer issues. Women who were breast cancer survivors and were located in the Greater Cincinnati area may become members by signing a consent form and completing a registration form that includes questions specific to the detection, diagnosis, and treatment of their disease. A total of 300 women listed in the BCRGC met the eligibility criteria of the study. All procedures were approved by the Wright State University Institutional Review Board prior to data collection.

\section{Data collection}

The 300 women who met the eligibility criteria and agreed to be contacted received a packet that included a cover letter, the McGill Quality of Life questionnaire [25], the Leeds Assessment of Neuropathic Symptoms and Signs questionnaire (LANSS) [26], a questionnaire to measure current exercise behaviors (Reigle), and a self-addressed, stamped envelope. Women were asked to return the completed questionnaires within two weeks of receiving the packet. Women who did not respond within two weeks were sent a reminder postcard.

\section{Data analysis}

Descriptive statistics have been computed as means and standard deviations. A Pearson's product moment correlation was used to determine the relationship between QOL and current exercise behaviors for the group as a whole. A student's T-test was used to compare the overall QOL ratings, as well as the prevalence of pain ratings, among patients who received the recommended amount of exercise compared to those who did not. All data was analyzed at the 0.05 level of significance.

\section{Results}

Of the 300 surveys sent out, 134 completed surveys were returned and analyzed, giving a $44.6 \%$ response rate. The characteristics of the patients are summarized in Table 1 . The distribution of QOL was normal. On average, patients reported exercising $2.3 \mathrm{~d} / \mathrm{wk}$ (approximately $69 \mathrm{~min} / \mathrm{wk}$ ) and rated their overall quality of life (QOL) as 4.7 on a 10-point scale. CIPN impacted routine activities, functions, and behaviors in the areas of domestic, work, and social/leisure life. A moderate correlation was measured between QOL and current exercise behaviors for the group as a whole $(\mathrm{r}=0.56)$. Table 2 summarizes the results of the Exercise Behaviors Survey for all respondents. Table 3 presents the results of the LANSS survey for all respondents.

Responses were analyzed to determine the percentage of patients completing the recommended amount of physical activity (at least 150 min moderate-intense ex/wk and muscle strengthening activity $2 \mathrm{~d} / \mathrm{wk}$

\begin{tabular}{|l|l|l|l|l|}
\hline $\begin{array}{l}\text { Age at time of } \\
\text { survey (yrs) }\end{array}$ & $\begin{array}{l}\text { Age at time of } \\
\text { diagnosis (yrs) }\end{array}$ & Education Level & Race & $\begin{array}{l}\text { Length of } \\
\text { Cancer } \\
\text { Treatment }\end{array}$ \\
\hline $54.9 \pm 2.4$ & $50.4 \pm 5.7$ & $\begin{array}{l}36=\text { high school } \\
68=\text { college } \\
30=\text { postgrad }\end{array}$ & $\begin{array}{l}\text { White =105 } \\
\text { Black = 21 } \\
\text { Hispanic =6 } \\
\text { Other = 2 }\end{array}$ & \\
\hline & & & \\
\hline
\end{tabular}

Table 1: Subject Characteristics. Values are means \pm SE.

\begin{tabular}{|l|l|}
\hline Type of Exercise & Frequency/wk \\
\hline Increase flexibility of arms and shoulders & $2.39 \pm 0.10$ \\
\hline Increase strength of arms and shoulders & $2.16+0.10$ \\
\hline Increase flexibility of legs & $2.48+0.11$ \\
\hline Increase strength of legs & $2.45+0.10$ \\
\hline Increase strength and flexibility of upper body & $2.16+0.10$ \\
\hline Increase strength and flexibility of lower body & $2.35+0.10$ \\
\hline Balance exercises & $2.03+0.11$ \\
\hline Resistance training & $1.97+0.09$ \\
\hline
\end{tabular}

Table 2: Results from Exercise Behaviors Survey. Values are means \pm SE.

\begin{tabular}{|l|l|}
\hline Questions & $\begin{array}{l}\text { \% of respondents } \\
\text { answering Yes }\end{array}$ \\
\hline $\begin{array}{l}\text { Would you describe your pain as pricking, tingling, pins and } \\
\text { needles? }\end{array}$ & $51 \pm 1.2 \%$ \\
\hline Does the skin in the painful areas look different than normal? & $17.9 \pm 0.5 \%$ \\
\hline \begin{tabular}{l} 
Is the skin sensitive to touch? \\
\hline $\begin{array}{l}\text { Does your pain come on suddenly in bursts when you are } \\
\text { still? }\end{array}$
\end{tabular} & $33.3 \pm 1.7 \%$ \\
\hline $\begin{array}{l}\text { Do you feel that skin temperature in the painful area has } \\
\text { changed? }\end{array}$ & $20.5 \pm 2.1 \%$ \\
\hline $\begin{array}{l}\text { Does stroking the affected area with cotton wool produce } \\
\text { pain? }\end{array}$ & $9.2 \pm 0.3 \%$ \\
\hline
\end{tabular}

Table 3: Results from LANSS Survey. Values are means \pm SE.

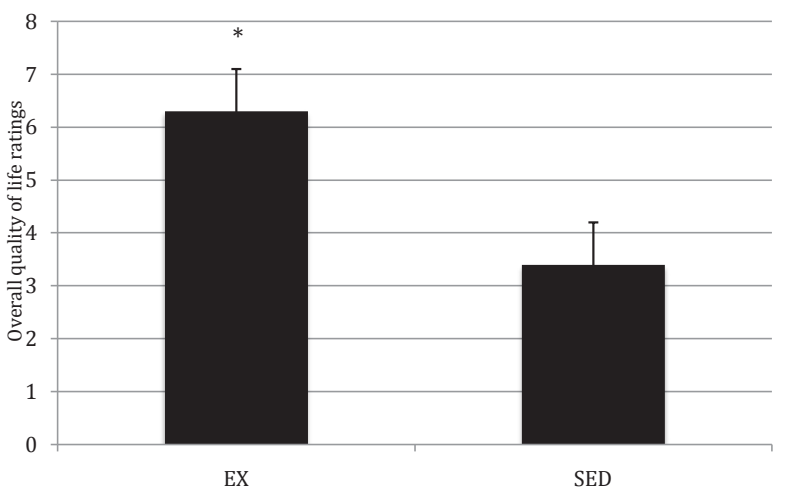

Figure 1: Overall Quality of Life Ratings. Values are means \pm SE. * $p<0.001$ vs. SED.

[27]. Approximately $15.6 \%$ of the patients surveyed reported meeting these recommended levels of physical activity $(E X, n=21)$. This group of patients reported an overall QOL of 6.3. As demonstrated in (Figure 1), this was significantly higher than those patients who did not meet these recommendations (SED, $\mathrm{n}=113$ ), who reported an average overall QOL of $3.4(p<0.001)$. Similarly, only $15 \%$ of EX patients reported experiencing pain compared to $72 \%$ of SED patients $(\mathrm{p}<0.001)$ (Figure 2). The pain was frequently described as "tingling" and "numbness" and localized to "hands and feet". Several respondents $(n=46)$ indicated that this pain was "better when I exercise". 


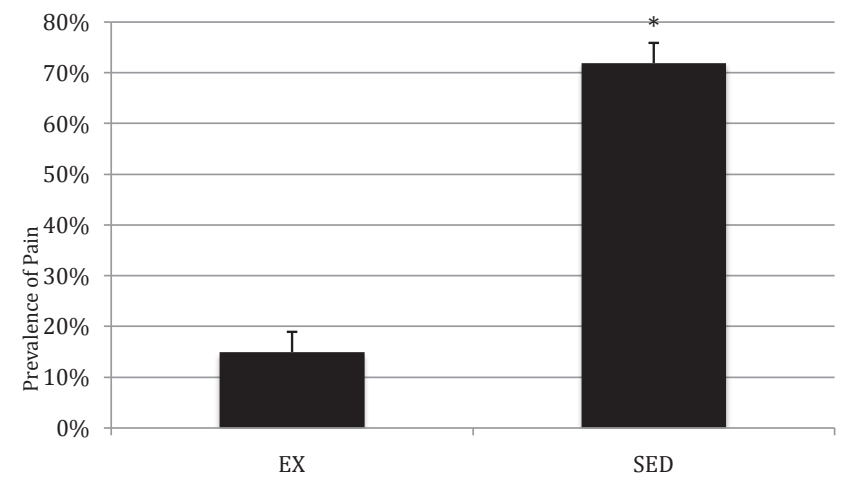

Figure 2: Prevalence of Pain Ratings. Values are means $\pm S E .{ }^{*} p<0.001$ vs. EX.

\section{Discussion}

The major finding in this investigation was that breast cancer patients with CIPN who received the recommended levels of physical activity reported a significantly higher overall QOL and experienced significantly less pain than their sedentary counterparts. CIPN affected breast cancer patients' routine activities, functions, and behaviors. While it is unknown if the sedentary individuals abstained from exercise because of their pain, the respondents who stated that their pain was "better when I exercise" indicates that it seems likely that an exercise intervention would be successful in attenuating symptoms of CIPN and improving the overall QOL of breast cancer patients.

With neuropathy, muscle mass atrophies and leads to significant decreases in muscular strength [28]. This decline in strength appears to be slow and progressive. It also appears to affect distal muscle groups more so than proximal muscles. Researchers have indicated that this muscle weakness translates into impaired motor performance skills and a reduced exercise capacity [29]. However, several studies have reported improvements in muscular strength following moderate resistance exercise programs in patients with hereditary motor and sensory neuropathies [30,31], as well as diabetic neuropathies, and those associated with fibromyalgia and chronic fatigue [32-37]. In light of these findings, many researchers recommend that exercise training serve as an important component in the comprehensive treatment plan for patients with peripheral neuropathy $[33,34,38]$. Moderate-to-intense strength training and aerobic exercise appears to be well tolerated by these patients [38], and is associated with improvements in motor function and nerve conduction velocity [32,35], as well as improved muscle reinnervation and increased axon regeneration [39]. In addition, one investigation reported that low intensity treadmill exercise promoted Schwann cell proliferation in the injured peripheral nerve [40]. In light of these findings, it is feasible to assume that an individual who has experienced a reduction in muscular strength and functional ability due to CIPN may experience similar improvements following an exercise program.

It is not uncommon for individuals with cancer to experience pain. This pain may be triggered by the disease itself, or by its associated treatments. The direct effect of the tumor accounts for about $70 \%$ of the pain related to cancer, while approximately $15 \%$ of cancer pain is related to its treatments [41]. The pain associated with CIPN has long been recognized as one of the more difficult types of pain to treat. However, as explained earlier, it is possible that exercise may have a beneficial effect on pain. As illustrated by the respondents in the cur- rent study, those individuals who exercised experienced significantly less pain than their sedentary counterparts. Likewise, it was noted that pain became "better" upon exercise. This finding is supported by several studies conducted on healthy populations, whereby pain thresholds and tolerance levels have been reported to increase both during and following exercise. In addition, intensity ratings of pain appear to decrease following exercise $[42,43]$.

While literature examining the role of exercise on symptoms of pain related to CIPN is lacking, we believe that the existing tangential research supports the use of exercise as a means to attenuate general cancer related pain. Exercise during cancer treatment has been shown to have a beneficial effect on pain for breast cancer patients [44-47]. In a similar study to ours, Liou et al. [45] surveyed the daily physical activity levels of individuals who were undergoing chemotherapy, but were not diagnosed with CIPN. These authors reported that those patients who received the recommended $150 \mathrm{~min} / \mathrm{wk}$ of moderate activity reported significantly less symptoms of pain than their sedentary counterparts.

In light of the findings and the literature surrounding this topic, it seems feasible to assume that a supervised exercise program would provide a beneficial effect on quality of life and pain associated with CIPN in breast cancer patients. More follow up investigations are warranted.

\section{Limitations}

The most apparent limitation in the present study is the low response rate from the breast cancer patients (44.6\%). However, in survey research, no single response rate is considered a standard [48]. Mail surveys typically have lower response rates than other types of surveys [49]. In the present study, non respondents were sent a reminder postcard in an attempt to increase the response rate; however, additional measures could have also been employed, such as personal contact. In addition, due to the lack of existing literature examining the effects of exercise on symptoms of CIPN, the authors had to look to the effects of exercise on symptoms of peripheral neuropathy in other chronic diseases (i.e., diabetes) to make its generalizations. Thus, it is possible that an exercise program may not produce similar results in a breast cancer patient. Likewise, since the location of cancer will vary the symptoms related to CIPN, it is possible that the exercise response would produce a different outcome in another form of cancer.

\section{References}

1. Kaley TJ, Deangelis LM (2009) Therapy of chemotherapy-induced periphera neuropathy. $\mathrm{Br} \mathrm{J}$ Haematol 145: 3-14.

2. Quasthoff S, Hartung HP (2002) Chemotherapy-induced peripheral neuropathy. J Neurol 249: 9-17.

3. Horowitz SH (2007) The diagnostic workup of patients with neuropathic pain Med Clin North Am 91: 21-30.

4. National Health \& Medical Research Council (1999) Acute pain management: Scientific evidence Australia. Commonwealth of Australia.

5. Verstappen CCP, Heimans JJ, Hoekman K, Postma TJ (2003) Neurotoxic complications of chemotherapy in patients with cancer: Clinical signs and optimal management. Drugs 63: 1549-1563.

6. Visovsky C (2003) Chemotherapy-induced peripheral neuropathy Nursing Perspectives. Cancer Investigation 21: 439-451.

7. Tolle T, Xu X, Sadosky AB (2006) Painful diabetic neuropathy: a cross-sectional survey of health state impairment and treatment patterns. J Diabetes Complications 20: 26-33.

8. Zelman DC, Gore M, Dukes E, Tai KS, Brandenburg N (2005) Validation of a modified version of the brief pain inventory for painful diabetic peripheral neuropathy. J Pain Symptom Manage 29: 401-410. 
Citation: Wonders KY, Drury DG (2012) Current Exercise Behaviors of Breast Cancer Patients Diagnosed with Chemotherapy-induced Peripheral Neuropathy. J Integr Oncol 1:103. doi:10.4172/2329-6771.1000103

Page 4 of 4

9. Goodman LS, Limbird LE, Milinoff PB ( 1996) (ed) Goodman and Gilman's The pharmacological basis of therapeutics. 9th ed New York NY: McGraw-Hil Professional.

10. Rao RD, Michalak JC, Sloan JA, Loprinzi CL, Soori GS, et al. (2007) Efficacy of gabapentin in the management of chemotherapy-induced peripheral neuropathy: a phase 3 randomized, double-blind, placebo-controlled, crossover tria (N00C3).. Cancer 110: 2110-2118.

11. Suzuki T, Nishio K, Tanabe S (2001) The MRP family and anticancer drug metabolism. Curr Drug Metab 2: 367-377.

12. Gustafsson T, Puntschart A, Kaijser L, Jansson E, Sundberg CJ (1999) Exercise-induced expression of angiogenesis-related transcription and growth factors in human skeletal muscle. Am J Physiol 276: H679-H685.

13. Fukai T, Siegfried MR, Ushio-Fukai M, Cheng Y, Kojda G, et al. (2000) Regulation of the vascular extracellular superoxide dismutase by nitric oxide and exercise training. J Clin Invest 105: 1631-1639.

14. Markes M, Brockow T, Resch KL (2006) Exercise for women receiving adjuvant therapy for breast cancer. Cochrane Database Syst Rev CD005001.

15. Irwin ML, Crumley D, McTiernan A, Bernstein L, Baumgartner R, et al. ( 2003 ) Physical activity levels before and after a diagnosis of breast carcinoma: the Health, Eating, Activity, and Lifestyle (HEAL) study. Cancer 97: 1746-1757.

16. Herrero F, San Juan AF, Fleck SJ, Balmer J, Perez M, et al. (2006) Combined aerobic and resistance training in breast cancer survivors: A randomized, controlled pilot trial. Int J Sports Med 27: 573-580.

17. Aitken DR, James AG (1997) Seromas and physiotherapy after mastectomy Ann Surg Oncol 4: 293-297.

18. Schneider CM, Dennehy CA, Roozeboom M, Carter SD (2002) A model program: exercise intervention for cancer rehabilitation. Integr Cancer Ther 1: 7682.

19. Schneider CM, Hsieh CC, Sprod LK, Carter SD, Hayward R (2007) Effects of supervised exercise training on cardiopulmonary function and fatigue in breast cancer survivors during and after treatment. Cancer 110: 918-925.

20. Schneider CM, Hsieh CC, Sprod LK, Carter SD, Hayward R (2007) Exercise training manages cardiopulmonary function and fatigue during and following cancer treatment in male cancer survivors. Integr Cancer Ther 6: 235-241.

21. Schneider CM, Hsieh CC, Sprod LK, Carter SD, Hayward R (2007) Cance treatment-induced alterations in muscular fitness and quality of life: the role of exercise training. Ann Oncol 18: 1957-1962.

22. Balducci S, lacobellis G, Parisi L, Di Biase N, Calandriello E, et al. (2006) Exercise training can modify the natural history of diabetic peripheral neuropathy. $J$ Diabetes Complications 20: 216-223.

23. Richardson JK, Sandman D, Vela S (2001) A focused exercise regimen improves clinical measures of balance in patients with peripheral neuropathy. Arch Phys Med Rehabil 82: 205-209.

24. Tesfaye S, Harris ND, Wilson RM, Ward JD (1992) Exercise-induced conduction velocity increment: A marker of impaired peripheral nerve blood flow in diabetic neuropathy. Diabetologia 35: 155-159.

25. Cohen SR, Mount BM, Strobel MG, Bui F (1995) The McGill Quality of Life Questionnaire: a measure of quality of life appropriate for people with advanced disease. A preliminary study of validity and acceptability. Palliat Med 9: 207-

26. Bennett M (2001) The LANSS Pain Scale: the Leeds assessment of neuropathic symptoms and signs. Pain 92: 147-157

27. Centers for Disease Control and Prevention (2011) How much physical activity do adults need?

28. del Porto LA, Nicholson GA, Ketheswaren P (2010) Correlation between muscle atrophy on MRI and manual strength testing in hereditary neuropathies. $J$ Clin Neurosci 17: 874-878.

29. Carter GT, Abresch RT, Fowler WM Jr, Johnson ER, Kilmer DD, et al. (1995) Profiles of neuromuscular diseases. Hereditary motor and sensory neuropathy, types I and II. Am J Phys Med Rehabil 74: S140-S149.

30. Lindeman E, Leffers P, Spaans F, Drukker J, Reulen J, et al. (1995) Strength training in patients with myotonic dystrophy and hereditary motor and sensory neuropathy: a randomized clinical trial. Arch Phys Med Rehabil 76: 612-620.
31. Kilmer DD, McCrory MA, Wright NC, Aitkens SG, Bernauer EM, et al. (1994) The effect of a high resistance exercise program in slowly progressive neuro-muscular disease. Arch Phys Med Rehabil 75: 560-563.

32. Fisher MA, Langbein WE, Collins EG, Williams K, Corzine L (2007) Physiologi-cal improvement with moderate exercise in type II diabetic neuropathy. Electro-myogr Clin Neurophysiol 47: 23-28.

33. Smith AG, Russell J, Feldman EL, Goldstein J, Peltier A, et al. (2006) Lifestyle intervention for pre-diabetic neuropathy. Diabetes Care 29: 1294-1299.

34. Spellman CW (2008) Aggressively managing type 2 diabetes mellitus, hyperlip-idemia, and bone loss. J Am Osteopath Assoc 108: S20-S27.

35. Van meeteren NL, Brakkee JH, Biessels GJ, Kappelle AC, Helders PJ et al. (1996) Effect of exercise training on acute (crush lesion) and chronic (diabetes mellitus) peripheral neuropathy in the rat. Restor Neurol Neurosci 10 85-93.

36. Cook DB, Nagelkirk PR, Poluri A, Mores J, Natelson BH (2006) The influence of aerobic fitness and fibromyalgia on cardiorespiratory and perceptual responses to exercise in patients with chronic fatigue syndrome. Arthritis Rheum 54: 3351-3362.

37. Cook DB, Stegner AJ, Ellingson LD (2010) Exercise alters pain sensitivity in Gulf War Veterans with chronic musculoskeletal pain. J Pain 11: 764-772.

38. Schenone A, Nobbio L, Monti Bragadin M, Ursino G, Grandis M (2011) Inherited neuropathies. Curr Treat Options Neurol 13: 160-179.

39. Udina E, Puigdemasa A, Navarro X ( 2011) Passive and active exercise im-prove regeneration and muscle reinnervation after peripheral nerve injury in the rat. Muscle Nerve 43: 500-509.

40. Seo TB, Oh MJ, You BG, Kwon KB, Chang IA, et al. (2009) ERK 1/2medated Schwann cell proliferation in the regenerating sciatic nerve by treadmill training. J Neurotrauma 26: 1733-1744.

41. Portenoy RK, Hagen NA (1990) Breakthrough pain: definition, prevalence and characteristics. Pain 41: 273-281.

42. Koltyn KF, Garvin AW, Gardiner RL, Nelson TF (1996) Perception of pain fol-lowing aerobic exercise. Med Sci Sports Exerc 28: 1418-1421.

43. Gurevich M, Kohn PM, Davis C (1994) Exercise-induced analgesia and the role of reactivity in pain sensitivity. J Sports Sci 12: 549-559.

44. Rief W, Bardwell WA, Dimsdale JE, Natarajan L, Flatt SW, et al. (2011) Long-term course of pain in breast cancer survivors: a 4-year longitudinal study. Breast Cancer Res Treat 130: 579-586.

45. Liou YM, Lee HL, Chien LY, Kao WY, Chiang CC, et al. (2011) Daily-life physical activity and related factors among patients with cancer receiving chemotherapy in Taiwan. Cancer Nurs 34: 443-452.

46. Courneya KS, Tamburrini AL, Woolcott CG, McNeely ML, Karvinen KH, et al (2011) The alberta physical activity and breast cancer prevention trial: Quality of life outcomes. Prev Med 52: 26-32.

47. Griffith K, Wenzel J, Shang J, Thompson C, Stewart K, et al. (2009) Impact of a walking intervention on cardiorespiratory fitness, self-reported physical func-tion, and pain in patients undergoing treatment for solid tumors. Cance 115: 4874-4884

48. Fink A (1995) How to sample in surveys. Thousand Oaks, CA: SAGE

49. Fowler FJ (1993) Survey research methods (2nd ed.). Thousand Oaks CA: SAGE. 